\title{
Diversity and abundance of photosynthetic sponges in temperate Western Australia
}

\author{
Marie-Louise Lemloh ${ }^{1}$, Jane Fromont ${ }^{2}$, Franz Brümmer*1 and \\ Kayley M Usher ${ }^{3}$
}

Address: ${ }^{1}$ Abteilung Zoologie, Biologisches Institut, Universität Stuttgart, Pfaffenwaldring 57, 70569 Stuttgart, Germany, ${ }^{2}$ Department of Aquatic Zoology, Western Australian Museum, Locked Bag 49, Welshpool DC, Western Australia 6986, Australia and ${ }^{3}$ School of Plant Biology, University of Western Australia, 35 Stirling Highway, Crawley, Western Australia 6009, Australia

Email: Marie-Louise Lemloh - Marie-Louise.Lemloh@bio.uni-stuttgart.de; Jane Fromont - jane.fromont@museum.wa.gov.au; Franz Brümmer* - franz.bruemmer@bio.uni-stuttgart.de; Kayley M Usher - kusher@cyllene.uwa.edu.au

* Corresponding author

Published: 5 February 2009

BMC Ecology 2009, 9:4 doi:10.1 186/1472-6785-9-4
Received: 9 July 2008

Accepted: 5 February 2009

This article is available from: http://www.biomedcentral.com/I472-6785/9/4

(c) 2009 Lemloh et al; licensee BioMed Central Ltd.

This is an Open Access article distributed under the terms of the Creative Commons Attribution License (http://creativecommons.org/licenses/by/2.0), which permits unrestricted use, distribution, and reproduction in any medium, provided the original work is properly cited.

\begin{abstract}
Background: Photosynthetic sponges are important components of reef ecosystems around the world, but are poorly understood. It is often assumed that temperate regions have low diversity and abundance of photosynthetic sponges, but to date no studies have investigated this question. The aim of this study was to compare the percentages of photosynthetic sponges in temperate Western Australia (WA) with previously published data on tropical regions, and to determine the abundance and diversity of these associations in a range of temperate environments.
\end{abstract}

Results: We sampled sponges on $5 \mathrm{~m}$ belt transects to determine the percentage of photosynthetic sponges and identified at least one representative of each group of symbionts using I6S rDNA sequencing together with microscopy techniques. Our results demonstrate that photosynthetic sponges are abundant in temperate WA, with an average of $63 \%$ of sponge individuals hosting high levels of photosynthetic symbionts and $11 \%$ with low to medium levels. These percentages of photosynthetic sponges are comparable to those found on tropical reefs and may have important implications for ecosystem function on temperate reefs in other areas of the world. A diverse range of symbionts sometimes occurred within a small geographic area, including the three "big" cyanobacterial clades, Oscillatoria spongeliae, "Candidatus Synechococcus spongiarum" and Synechocystis species, and it appears that these clades all occur in a wide range of sponges. Additionally, spongin-permeating red algae occurred in at least 7 sponge species. This study provides the first investigation of the molecular phylogeny of rhodophyte symbionts in sponges.

Conclusion: Photosynthetic sponges are abundant and diverse in temperate WA, with comparable percentages of photosynthetic to non-photosynthetic sponges to tropical zones. It appears that there are three common generalist clades of cyanobacterial symbionts of sponges which occur in a wide range of sponges in a wide range of environmental conditions. 


\section{Background}

Sponges (Phylum Porifera) are sessile aquatic metazoans that are found in all aquatic habitats and have important roles in marine ecological processes. Fossil records dating back to the Late Cambrian era 509 million years ago show that sponges have survived largely unchanged in their general structural organization [1]. So far about 7,000 extant species are described [2]. As filter feeders, sponges filter food particles from the water pumped through their body and bacteria are the main component of the sponge diet $[3,4]$.

Photosynthetic sponges are very diverse in terms of the taxonomy of hosts and symbionts and their biogeography, occurring around the world in tropical and temperate oceans. They occupy a similar niche to hard corals, being filter-feeding benthic primary producers that provide food and shelter for a range of reef organisms. Photosynthetic symbionts include cyanobacteria, dinoflagellates, rhodophytes, chlorophytes and diatoms [5-7]. These symbionts provide photosynthates [8-10] and possibly fixed nitrogen [11] to the sponge host. In addition to donating energy and carbon, cyanobacteria may benefit sponges by the production of secondary metabolites that act as antibacterials and deter predators $[12,13]$.

The most common group of photosynthetic symbionts in sponges are the cyanobacteria, occurring in at least 38 sponge genera belonging to the Classes Calcarea and Demospongiae [14,15]. Despite their apparent importance to many sponges, only two sponge species (Chondrilla australiensis and Diacarnus erythraenus) have been studied to determine how they acquire their cyanobacterial symbionts. Vertical transmission, which is considered to be an indicator for mutualism [16], was demonstrated in both sponge species using transmission electron microscopy (TEM) and molecular techniques [17-19]. This passage of the symbiont from parent to offspring may benefit sponge larvae by providing photosynthetically fixed energy before they are able to feed, in addition to benefiting the sessile adult sponges. Vertical transmission via sponge larvae has also been shown for an alphaproteobacterial symbiont common to many marine sponges [20].

It is not known conclusively if sponges that vertically transmit symbionts are able to recognise them. Many sponges harbor large numbers of extracellular bacteria in their mesohyl, and if they are fed these bacteria together with food bacteria, the sponges are able to discriminate between them [21-23]. This suggests that the symbionts are either "invisible" to the sponge due to a physical capsule or molecular shield (suggestions only), or that the sponge is able to recognize them as symbionts. It is likely that different symbionts have evolved different strategies for co-existing with sponges. Recent studies using molecular techniques show that symbiotic microorganisms in sponges are phylogenetically diverse and that sponge-specific microbial communities exist that are different from that of seawater $[7,15,24]$.

A phylogenetic analysis of sponge derived cyanobacterial $16 S$ rDNA sequences showed that more than three-quarters fell into monophyletic, sponge-specific clusters [7]. For one cluster of symbiotic cyanobacteria the name 'Candidatus Synechococcus spongiarum' was proposed [25] as this species has not been found in water samples and is phylogenetically distinct from its nearest free-living Synechococcus relative [26]. Recent research demonstrates that this is the most common cyanobacterial symbiont in sponges, occurring around the world [7]. Other important cyanobacterial symbionts are the filamentous Oscillatoria spongeliae and the relatively large coccoid Synechocystis trididemni, a symbiont also found in ascidians.

Photosynthetic sponges are common in tropical regions [27] and many of these sponges may derive a significant proportion of their nutrition from their photosynthetic symbionts [8]. Wilkinson [28] proposed that phototrophic sponges are more abundant in oligotrophic waters than in areas with high nutrient levels, and this appears to have lead to the assumption that they are largely restricted to tropical and sub-tropical zones [29]. Although photosynthetic sponges have been well documented in tropical regions to our knowledge only one study has investigated their abundance in a temperate region. Roberts and colleagues [29] estimated that over $65 \%$ of temperate reef sponges from New South Wales, Australia, may contain photosynthetic symbionts. Polar regions represent another unique environment for sponge symbioses. Webster et. al. [30] reported diatoms and dinoflagellates in Antarctic sponges, but do not report cyanobacterial symbionts. Several other studies [31-33] have also demonstrated the presence of symbiotic diatoms in Antarctic sponges.

The existence of sponge-specific microorganisms has been accepted but many gaps remain in our knowledge of the identity of the symbionts, the mechanisms that affect the microbial diversity in the sponges, and the physiology of the symbionts. In this study we use the term 'symbiosis' as the intimate association of two organisms, including mutualisms and parasitism. The aim of this study was to determine the percentages of photosynthetic sponges in a temperate region and compare this with previous studies of tropical regions, and to explore the biodiversity of photosynthetic symbionts of sponges and their relative abundance in temperate south-western Australian waters. $5 \mathrm{~m}$ belt transects with high numbers of sponges were selected 
and studied using optical and molecular techniques. Additionally, in situ measurements of photosynthetic activity were carried out for some sponges using a Diving PAM (pulse-amplitude-modulation) fluorometer.

\section{Methods}

\section{Sponge collection and preservation}

$5 \mathrm{~m}$ belt transects were located in coastal areas of temperate southern Western Australia in depths ranging from 3 $\mathrm{m}$ to $8.2 \mathrm{~m}$ and with different ecological conditions (see Table 1). Sponge samples that were directly under the $5 \mathrm{~m}$ transect line or approximately $30 \mathrm{~cm}$ beside the line were collected. The study areas were located in the Perth metropolitan region $\left(32^{\circ} 03^{\prime} \mathrm{S}, 115^{\circ} 45^{\prime} \mathrm{E}\right)$, Busselton Jetty $\left(33^{\circ} 30^{\prime} \mathrm{S}, 115^{\circ} 10^{\prime} \mathrm{E}\right)$, and Eagle Bay, near Busselton (33⒊036'S, $\left.115^{\circ} 04.056^{\prime} \mathrm{E}\right)$ (Table 1 . Please see Ref. [26] for map) and were investigated using SCUBA. These areas have high chlorophyll $a$ levels all year indicating the presence of nutrients, and levels are particularly high in the winter months when rainfall and run-off washes fertilizers and other nutrient sources into the ocean [34]. The light level categories 'low', 'medium' and 'high' were determined at the study sites based on the presence of caves or overhangs and depth. A diving pulse-amplitudemodulated (PAM) fluorometer was used whenever possible to determine the presence of photosynthesis in sponges, and samples were only collected from sponges with a positive result. Where the PAM was not used all sponges on the transect were collected and assessed in the laboratory for photosymbionts using fluorescence microscopy. Each sample was divided into four parts and preserved in $75 \%$ ethanol, saturated DMSO solution $\mathrm{pH} 7.5$ (20\% DMSO, $0.25 \mathrm{M} \mathrm{Na}_{2}$ EDTA pH 8, NaCl to saturation), $2.5 \%$ glutaraldehyde and $-20^{\circ} \mathrm{C}$ on return to shore. All samples were collected with permissions and are stored at the Western Australian Museum.

\section{PAM fluorometry}

An underwater pulse-amplitude-modulated (PAM) fluorometer (Diving-PAM, Walz GmbH, Germany) was used on all sponges on transects $\mathrm{EB}, \mathrm{BJ}$ and $\mathrm{Mn}$ prior to sampling to determine which sponges were positive for photosynthesis. This allowed us to sample only sponges with photosynthetic symbionts, preventing unnecessary environmental damage and saving time. Sponges with visible surface contamination were brushed with a tooth brush before PAM readings were taken. To record rapid light curves a surface holder "DIVING-SH" was fixed on the sponge. Rapid light curves first measured the maximal YIELD in the absence of actinic light, followed by a series of 8 consecutive YIELD-measurements with increasing light intensity. The measuring intensity was 12 and the saturating light pulse intensity was 10 (width 0.8 seconds). The actinic light intensity at the beginning of the light curve measurement was 2 and the step width was 10 seconds. If the YIELD was less than 0.1 at the beginning of the measurement the sample was defined as 'negative' for photosynthetic symbionts. These sponges were noted, but not collected. As we lacked the equipment necessary to determine absorbance and reflection of light of different sponges, absolute levels of photosynthetic efficiency could not be determined.

\section{Light Microscopy}

All samples were analyzed via fluorescence microscopy to determine the presence, distribution and density of photosynthetic symbionts. Fresh sponge samples were washed with autoclaved sea water and cross sections were cut thinly using a double-sided razor. The sections were examined by fluorescence microscopy using a Leitz Diaplan microscope (Leica Microsystems, Germany). Blue light, using a I3 filter block (450-490 nm excitation filter and 515 barrier filter), and green light, using a N2.1 filter block (515-560 nm excitation filter and 590 barrier filter), were used to detect the distribution and concentration of autofluorescent cyanobacterial or algal pigments. Cyanobacterial and rhodophyte autofluorescence appeared orange-yellow using blue light due to the presence of phycobiliproteins, and were red in colour using green light, while algae (other than rhodophytes) appeared red in blue light. All samples were categorized according to a subjective analysis of the levels of autofluorescence from photosynthetic pigments (Table 2) and the categories 'low', 'medium' and 'high' were given to describe the densities of symbionts. Samples with no autofluorescence and ambiguous samples (very low

Table I: Transect locations: $5 \mathbf{m}$ belt transects conducted in coastal areas of the Perth metropolitan region and Busselton area.

\begin{tabular}{lllll}
\hline Transect label & Location & Depth & Light level & Study site \\
\hline WPI & Woodman Point & $3.0 \mathrm{~m}$ & High & West/North-West facing gently sloping wall, limestone boulders, high sedimentation rate \\
WP2 & Woodman Point & $7.0 \mathrm{~m}$ & High & West/North-West facing gently sloping wall, limestone boulders, high sedimentation rate \\
SMI & South Mole & $5.7 \mathrm{~m}$ & Low & South facing wall with overhang \\
SM2 & South Mole & $7.8 \mathrm{~m}$ & Full Sun & Open sandy flat bottom \\
EB & Eagle Bay & $7.2 \mathrm{~m}$ & Full Sun & Upper surface of large rock \\
BJ & Busselton Jetty & $6.9 \mathrm{~m}$ & Medium & Jetty pylons \\
Mn* & Mindarie & $8.2 \mathrm{~m}$ & Medium & West/South-West facing overhang \\
\hline
\end{tabular}

*Transect Mn was only $3 \mathrm{~m}$ in length. 
Table 2: Transect results: Number of individuals and species of photosynthetic sponges at different sampling sites.

\begin{tabular}{|c|c|c|c|c|c|c|c|c|c|}
\hline \multirow[t]{2}{*}{ Transect label } & \multirow[t]{2}{*}{ Light level } & \multicolumn{4}{|c|}{ Individuals } & \multicolumn{4}{|l|}{ Species } \\
\hline & & total & $P$ & L-M & $\mathrm{N}$ & total & $P$ & L-M & $\mathrm{N}$ \\
\hline WPI & High Light & 31 & 22 & 3 & 6 & 8 & 2 & 3 & 3 \\
\hline WP2 & High Light & 20 & 11 & I & 8 & 7 & 2 & I & 4 \\
\hline SMI & Low & 19 & 15 & 3 & I & 6 & 2 & 3 & 1 \\
\hline SM2 & Full Sun & 11 & 2 & 6 & 3 & 5 & 2 & 2 & 1 \\
\hline $\mathrm{Mn}$ & Medium & 20 & 9 & 3 & 8 & 11 & 5 & 1 & 5 \\
\hline$E B$ & Full Sun & 26 & 21 & 0 & 5 & 18 & 13 & 0 & 5 \\
\hline BJ & Medium & 15 & 9 & 0 & 6 & 14 & 8 & 0 & 6 \\
\hline Totals: & & $\begin{array}{l}142 \\
(100 \%)\end{array}$ & $\begin{array}{l}89 \\
(63 \%)\end{array}$ & $\begin{array}{l}16 \\
(11 \%)\end{array}$ & $\begin{array}{l}37 \\
(26 \%)\end{array}$ & 69 & 34 & 10 & 25 \\
\hline Number of different species: & & & & & & $63(100 \%)$ & 30 (48\%) & $10(16 \%)$ & $23(36 \%)$ \\
\hline
\end{tabular}

P: high levels of autofluorescence, L-M: low to medium levels of autofluorescence, N: no autofluorescence.

autofluorescence or potential surface contamination) were called 'negative'.

\section{Transmission Electron Microscopy}

Fresh sponge biopsies $\left(\sim 2 \mathrm{~mm}^{3}\right)$ were fixed in $2.5 \% \mathrm{EM}$ grade glutaraldehyde in $0.05 \mathrm{M}$ phosphate buffer $\mathrm{pH} 7.0$ (0.05 $\mathrm{M} \mathrm{NaH}_{2} \mathrm{PO}_{4}$ and $0.05 \mathrm{M} \mathrm{Na}_{2} \mathrm{HPO}_{4}$ ) for 3 hours then post-fixed with $1 \% \mathrm{O}_{\mathrm{s}} \mathrm{O}_{4}$ in $0.05 \mathrm{M}$ phosphate buffer for 1 $1 / 2$ hours. The specimens were dehydrated in an ethanol series and $100 \%$ propylene oxide, then embedded in Spurr's resin [35]. Ultra-thin sections $(90-150 \mathrm{~nm})$ were cut using a Reichert ultramicrotome (Leica, Ultracut) with glass knifes. Sections were transferred to naked copper grids $(75 \times 300$ mesh $)$ and stained with $1 \%$ aqueous uranyl acetate for 15 minutes and lead citrate [36] in carbon dioxide free conditions for 10 minutes. The specimens were washed in double distilled water and air dried, before examination with a JEOL 2000 FX electron microscope (JOEL Ltd., Japan) operating at $80 \mathrm{kV}$.

\section{PCR}

To avoid surface contamination the sponge samples were brushed with a toothbrush and rinsed with distilled water. Distribution of symbionts in the sponge tissue was examined via fluorescence microscopy and, where possible, about $1 \mathrm{~mm}$ of the sponge surface was removed with a double-sided razor to reduce surface contamination. Approximately $1 \mathrm{~mm}^{3}$ pieces of sponge tissue were placed directly into the PCR reaction mixes after soaking in $\mathrm{ddH}_{2} \mathrm{O}$ for 5 minutes. Cyanobacterial-specific primers were used to amplify cyanobacterial DNA in sponges. The forward primer cya359F (5'-GGGGAATYTTCCGCAATGGG) [37] and the reverse primer cya1459R (5'GGTAAYGACTTCGGGCRT) [38] were used to amplify a 1100 base pair section of the small subunit of ribosomal RNA (16S rDNA). For Denaturing Gradient Gel Electrophoresis (DGGE) a 40-nucleotide GC clamp (5'CGCCCGCCGCGCGCGGCGGGCGGGGCG-
GGGGCACGGGGGG-3') was added to the forward primer cya359F and used with the reverse primer cya781 [37]. $25 \mu \mathrm{l}$ PCR reactions contained final concentrations of $0.08 \mathrm{U} / \mu \mathrm{l}$ BIOTAQ DNA Polymerase (BIOLINE Australia), $1 \times \mathrm{NH}_{4}$ Buffer, $2 \mathrm{mM}$ dNTP mix, $2.5 \mathrm{mM} \mathrm{MgCl}{ }_{2}$ and $0.6 \mu \mathrm{M}$ of each oligonucleotide primer. The following program was used to amplify cyanobacterial DNA: one cycle of $94^{\circ} \mathrm{C}$ for $4 \mathrm{~min}, 60^{\circ} \mathrm{C}$ for $2 \mathrm{~min}$ and $72^{\circ} \mathrm{C}$ for 2 min followed by 30 cycles of $94^{\circ} \mathrm{C}$ for $1 \mathrm{~min}, 60^{\circ} \mathrm{C}$ for 1 $\min$ and $72^{\circ} \mathrm{C}$ for $1 \mathrm{~min}$. The program ended with $72^{\circ} \mathrm{C}$ for $4 \mathrm{~min}$ and a $4^{\circ} \mathrm{C}$ store. For DGGE the following PCR program was used: $95^{\circ} \mathrm{C}$ for $15 \mathrm{~min}$, followed by $94^{\circ} \mathrm{C}$ for $1 \mathrm{~min}, 68^{\circ} \mathrm{C}$ for $1 \mathrm{~min}$ and $72^{\circ} \mathrm{C}$ for $2 \mathrm{~min}$. For each subsequent cycle the temperature of annealing was reduced by $1^{\circ} \mathrm{C}$ until it reached $60^{\circ} \mathrm{C}$, whereupon the cycle was repeated 22 times. The PCR was ended with an extension step at $72^{\circ} \mathrm{C}$ for 10 minutes and a $4{ }^{\circ} \mathrm{C}$ hold. All PCR reactions were carried out under $\mathrm{S} 1$ conditions at CSIRO laboratories.

\section{Denaturing Gradient Gel Electrophoresis}

$20 \mu \mathrm{L}$ of PCR product were added to $10 \mu \mathrm{L}$ of loading buffer and run on a $7 \%$ polyacrylamide gel with a denaturing gradient of 20 to $60 \%$. The wells and the top of the gel were formed with $0 \%$ urea. The gel was run for 3.5 hours at $180 \mathrm{~V}$, then stained in $20 \mathrm{mg}$ of ethidium bromide $/ \mathrm{ml}$ in $1 \times$ TAE ( $40 \mathrm{mM}$ Tris- $\mathrm{HCl}, 20 \mathrm{mM}$ acetic acid, $1 \mathrm{mM}$ EDTA pH 8) for 15 minutes. Bands were visualised on a UV transilluminator, excised, placed in $15 \mu \mathrm{L}$ of $\mathrm{dd} H 2 \mathrm{O}$ and stored at $-20^{\circ} \mathrm{C}$ for sequencing reactions.

\section{Sequencing}

PCR products were purified using a QIAquick PCR Purification Kit (QIAGEN, Germany) as per manufacturers instructions, the DNA quantified with a NanoDrop spectrophotometer (ND-1000 NanoDrop Technologies, USA), and 10-20 ng of product used as a template for direct sequencing reactions. Sequencing reactions were 
analysed using an ABI automated sequencer (Applied Biosystems, USA) at a commercial facility (Royal Perth Hospital, West Australian Genome Resource Centre). Both DNA strands were sequenced using the original primers and a $10 \mu \mathrm{l}$ reaction mix containing $2 \mu \mathrm{l}$ of BigDye Terminator Mix (BDTM) version 3.1 (Applied Biosystems, USA). Chromatographs were checked by eye using the software Chromas Lite version 2.0 and ambiguous parts were removed. The basic local alignment search tool (BLAST) [39] was used to compare sample sequences to other bacterial sequences found on the database NCBI (National Center for Biotechnology Information). Pairwise comparisons were made with EMBL-EBI Emboss Pairwise Alignment Algorithms http://www.ebi.ac.uk/ emboss/align. Sequences were deposited in the GenBank database under the following accession numbers: $\underline{\text { EU383035 to EU383052. }}$

\section{Results}

\section{Abundance of photosynthetic sponges}

A total of 63 different sponge species from 7 transects were examined for the presence of photosymbionts. 30 sponge species had high levels of autofluorescence and were categorized as 'positive' for photosymbionts (48\%). 10 species had 'low to medium' levels of autofluorescence (16\%) and 23 species were 'negative' (36\%) (Table 2). Samples with a positive PAM fluorometry result had medium to high cyanobacterial autofluorescence. The observation of sponges with low to medium levels of autofluorescence, and correspondingly low PAM readings, was unexpected. As the nature of these associations is not known, we did not count these sponges as positive or negative for photosynthetic symbioses, but made a separate category for them.

Between 2 and 22 photosynthetic sponge individuals and 2 to 13 photosynthetic sponge species occurred on the transects, and the percent and number of photosynthetic sponge species was higher for the southern sites at Eagle Bay and Busselton Jetty (Table 2). Of the photosynthetic sponges only three species, Chondrilla australiensis, Chondropsis sp. and Mycale sp., occurred on more than one transect. However, other photosynthetic sponges were observed at multiple sites, but did not occur on more than one transect line. Many sponges could not be identified to known species, and probably represent previously poorly described or new species.

\section{Types of photosynthetic symbionts in sponges: Molecular} and microscopy results

Sequences were obtained for the symbionts of 10 photosynthetic sponges. Symbionts from Crella sp., a Calcarea species, Lissodendoryx sp., Phyllospongia sp., Cymbastela marshae and Hippospongia sp. were sequenced directly using the primers cya359F and cya1459R. The sequencing of symbionts in a number of other sponges was problematic and may have been caused by multiple factors including, in some instances, the presence of more than one type of symbiont. DGGE of amplified 16SrDNA from 7 sponges was performed (Figure 1) where this was suspected. Sequencing of the resulting bands was successful for Spongia sp., Mycale sp. 1, Chondropsis sp., Xestospongia sp., and Psammastra sp., resulting in sequences less than $450 \mathrm{bp}$. An overview of these results is given in Table 3.

\section{Synechococcus species}

The cyanobacterial symbionts of Crella sp. (transect WP1) and an unidentified Calcarea species (EB) were identified as two different Synechococcus strains with 16S rDNA analysis (Table 3). Crella sp. only had medium levels of cyanobacterial autofluorescence and the symbiont sequence resulted in a close GenBank match with the free-living Synechococcus strain WH 8016 (99.6\% sequence similarity to accession number AY172834). The $16 \mathrm{~S}$ rDNA sequence of the Calcarea species symbiont resulted in $98.8 \%$ sequence similarity to another free-living Synechococcus (accession number DQ248009.1). This sponge had high levels of cyanobacterial autofluorescence and a relatively high PAM reading of 6.5 maximal relative ETR (electron transport rate).

Cyanobacterial symbionts belonging to the "Candidatus Synechococcus spongiarum" clade were identified in four sponge species: Hippospongia sp., Phyllospongia sp., Psammastra sp. and Chondrilla australiensis, based on 16S rDNA sequencing and BLAST searches. All were closely related to

Table 3: Overview of the I6S rDNA sequencing results of sponge symbionts in temperate Western Australia.

\begin{tabular}{llll}
\hline Symbionts & Sponges & & \\
\hline Synechoccus spongiarum clade & Chondrilla australiensis* & Hippospongia sp. & Phyllospongia sp. \\
Synechococcus species & Calcarea species & Crella sp. & Paliclona sp.* \\
Synechocystis species & Mycale sp. I & Spongia sp. & \\
Oscillatoria spongeliae clade & Chondropsis sp. & \\
Undescibed cyanobacterium & Cymbastela marshae & \\
Rhodophyte & Lissodendoryx sp. & \\
\end{tabular}

*These symbionts were sequenced by Usher et al. (2004a). 


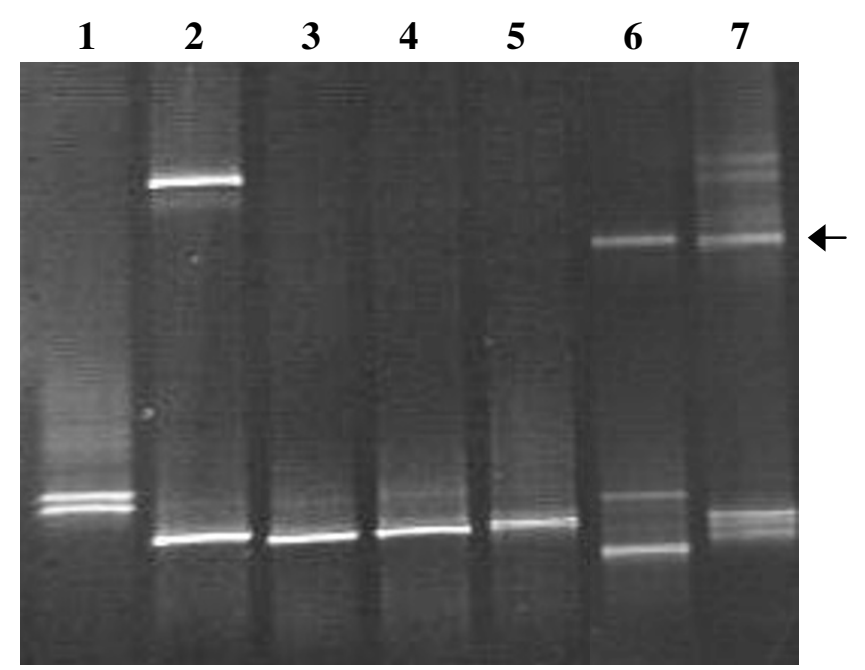

Figure I

DGGE of cyanobacterial symbionts. I6S rDNA Denaturing Gradient Gel Electrophoresis of cyanobacterial symbionts occurring in sponges in this study. I: Host = Spongia sp. Both high and low bands $=$ Synechocystis sp., differing by 2 base pairs. 2: Host $=$ Chondropsis sp. High band = uncultured phototrophic diatom. Low band = Oscillatoria spongeliae. 3: Host = Psammastra sp., symbiont = "Candidatus Synechococcus spongiarum". 4: Host = Chondrilla australiensis, symbiont = "Candidatus Synechococcus spongiarum". 5. Host = Chondropsis sp., symbiont = Oscillatoria spongeliae. 6. Host $=$ Xestospongia sp. High band = uncultured sponge bacterium. Medium band not able to be sequenced, appearance matches Synechocystis. Low band = chloroplast. 7: Host $=$ Mycale sp. I High (arrow) and middle bands = Synechocystis sp., $96.6 \%$ similarity to each other.

existing sequences for this symbiont on GenBank, with similarities over 99\%. All four sponge species showed high concentrations of small unicellular coccoid cyanobacteria with fluorescence microscopy. TEM of S. spongiarum in Hippospongia sp. showed intercellular cyanobacteria about $1 \mu \mathrm{m}$ long with 4 thylakoid spirals and typical ultrastructure for this symbiont. Some were observed dividing by binary fission (Figure $2 \mathrm{a}$ and $2 \mathrm{~b}$ ).

Synechococcus-like cyanobacteria were the most common photosynthetic symbionts found in this study. Other sponges that contained medium or high levels of small single-celled cyanobacteria resembling Synechococcus by light and fluorescence microscopy included an Aplysinidae species, Lissodendoryx (Anomodoryx) sp., Halichondrida (Dictyonellidae?), Tethya sp., Dendrilla sp., Haliclona (Haliclona) sp., Xestospongia sp. and Callyspongia sp. however, these were not sequenced.

\section{Oscillatoria spongeliae clade}

Oscillatoria spongeliae was sequenced from one species of Chondropsis, and had a GenBank similarity score of 99.3\% to a sponge-associated Oscillatoria spongeliae accession number AY615504 [40]. Fluorescence microscopy showed high concentrations of intercellular cyanobacteria, and TEM of Chondropsis sp. showed trichomes approximately $4 \mu \mathrm{m}$ in diameter containing 3 or more cells of variable length (not shown). Their ultrastructure was similar to those in Rützler [6], with domed terminal cells, thylakoids radiating from the centre of cells, and carboxysomes sometimes observed. Phycobiliproteins apparently leak from cells when samples are frozen, causing high background autofluorescence.

\section{Synechocystis species}

16S rDNA DGGE of Spongia sp. symbionts resulted in two bands (Figure 1) that, when sequenced, were only 2 base pairs different. The highest identity score from a BLAST search was $97.4 \%$ with the 16S rDNA gene of Synechocystis trididemni (accession number AB011380). High numbers of intercellular single-celled cyanobacteria were observed using fluorescence microscopy, and vacuolated, non-spiral thylakoid membranes were observed with TEM (not shown). Mycale sp. 1 contained two different Synechocystis species that had $94.3 \%$ and $96.7 \%$ similarity to Synechocystis trididemni (accession number AY845229), and had $96.6 \%$ similarity to each other. Fluorescence and light microscopy revealed smaller green coccoid cyanobacteria about $10 \mu \mathrm{m}$ in diameter, and a larger red coccoid symbiont approximately $15 \mu \mathrm{m}$ in diameter growing in close proximity (Figure 3). Autofluorescence also differed between these symbionts, with the red cyanobacteria emitting orange/red wavelengths and the green cyanobacteria emitting yellow/green wavelengths. High numbers of Synechocystis-like cyanobacteria were also observed in Xestospongia sp. and Phorbas sp. by fluorescence and light microscopy.

\section{Unknown Symbionts}

Cymbastela marshae contained a symbiont with $99.7 \% 16 \mathrm{~S}$ rDNA similarity to the symbiont previously found in Cymbastela marshae from Fremantle (accession number AY190174; [19]). This symbiont has $98.6 \%$ sequence identity to Oscillatoria rosea and $97 \%$ sequence identity to a Synechococcus sp. (accession number $\underline{\mathrm{AF} 448076}$ ).

DGGE using 16S rDNA resulted in three bands for a Xestospongia sp. (Figure 1). One band had 99\% sequence similarity to an uncultured sponge bacterium, another closely matched a chloroplast sequence. Sequencing was not successful for the third band. Other types of photosynthetic symbiont may occur, as this study restricted sequencing to representatives of the major groups. 

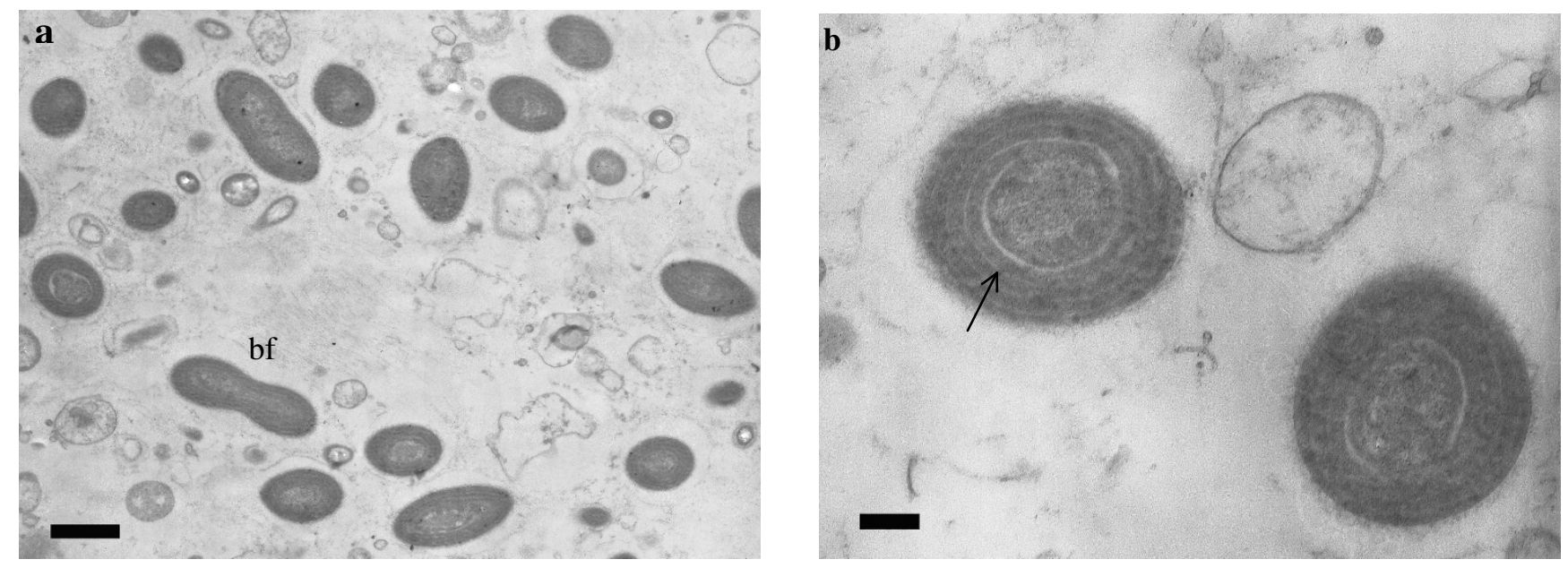

\section{Figure 2}

Symbiont in Hippospongia sp. a) TEM analysis for Hippospongia sp. showing cyanobacterial symbionts belonging to the "Candidatus Synechococcus spongiarum" clade as single cells and during division (bf = binary fission), scale bar $=1 \mu \mathrm{m}$. b) TEM showing two symbionts with thylakoid spirals (indicated by arrow), scale bar $=200 \mathrm{~nm}$.

\section{Red Algae}

A rhodophyte species was found to be associated with the sponge Lissodendoryx sp. The maximum GenBank identity score was $95 \%$ for the accession number $\underline{\text { AY731518, the }}$ $16 \mathrm{~S}$ rDNA gene of Palmaria palmata (Rhodophyta). Fluorescence microscopy indicated that similar symbionts also occurred along the spongin fibres of Crella sp., Clathria sp., Mycale sp. 2 (Figure 4a), Dictyodendrilla sp. and Iotro-

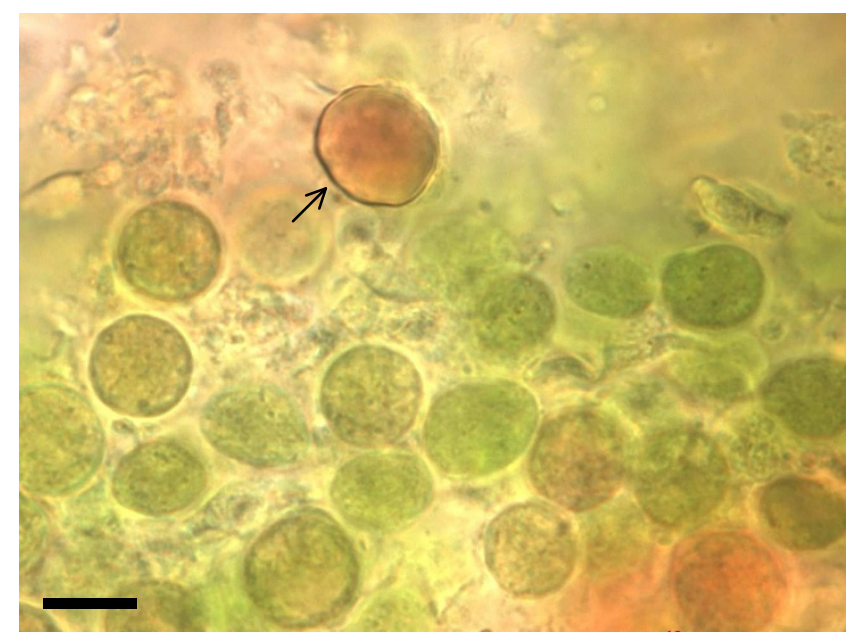

Figure 3

Synechocystis sp. Symbionts. Light microscopy image of two Synechocystis species in Mycale sp. I: smaller green coccoid and larger red coccoid symbionts (indicated by arrow), scale bar $=10 \mu \mathrm{m}$. chota cf. baculifera. Sponge skeletons appear red where the densities of rhodophytes are high. TEM observations show the rhodophytes occur inside spongin fibres, splitting them as they grow (Figure $4 \mathrm{~b}$ ), although it is not known if this always occurs. The ultrastructure of the symbionts is similar to Acrochaetium spongicolum in Mycale laxissima observed by Rützler [6]. Both Lissodendoryx sp. and Mycale sp. 2 were semi-translucent and encrusting or fanshaped, however rhodophytes were observed throughout the matrix of several densely pigmented sponges. Two species of Clathria sp. and one Crella sp. were opaque orange and a Dictyodendrilla sp. was opaque grey. Dictyodendrilla sp. was the only species harboring rhodophytes without siliceous spicule bundles within the fibres. This sponge had relatively low PAM readings (relative ETR of 2.2) in comparison to Mycale sp. 2 (Figure 5).

\section{PAM fluorometry}

Both Psammastra sp. and Phyllospongia sp. hosted Synechococcus spongiarum and occurred in close proximity in the same light conditions. However, the recorded light curves show saturation for Psammastra sp. at around $163 \mu \mathrm{mol}$ quanta $\mathrm{m}^{-2} \mathrm{~s}^{-1}$ with a maximal relative ETR of 7.8 while Phyllospongia sp. saturated at $120 \mu \mathrm{mol}$ quanta $\mathrm{m}^{-2} \mathrm{~s}^{-1}$ with a maximal relative ETR of 8.4 (Figure 5). The light curve for Cymbastela marshae (symbiont Oscillatoria sp.) showed saturation of photosynthetic electron transport at around $163 \mu \mathrm{mol}$ quanta $\mathrm{m}^{-2} \mathrm{~s}^{-1}$ and the maximal relative electron transport rate was 11.2. Spongia sp. hosted a Synechocystis trididemni like symbiont and saturated at $120 \mu \mathrm{mol}$ quanta $\mathrm{m}^{-2} \mathrm{~s}^{-1}$ with a maximal relative ETR of 4.9. Using molecular techniques a Synechococcus sp. was detected in a 

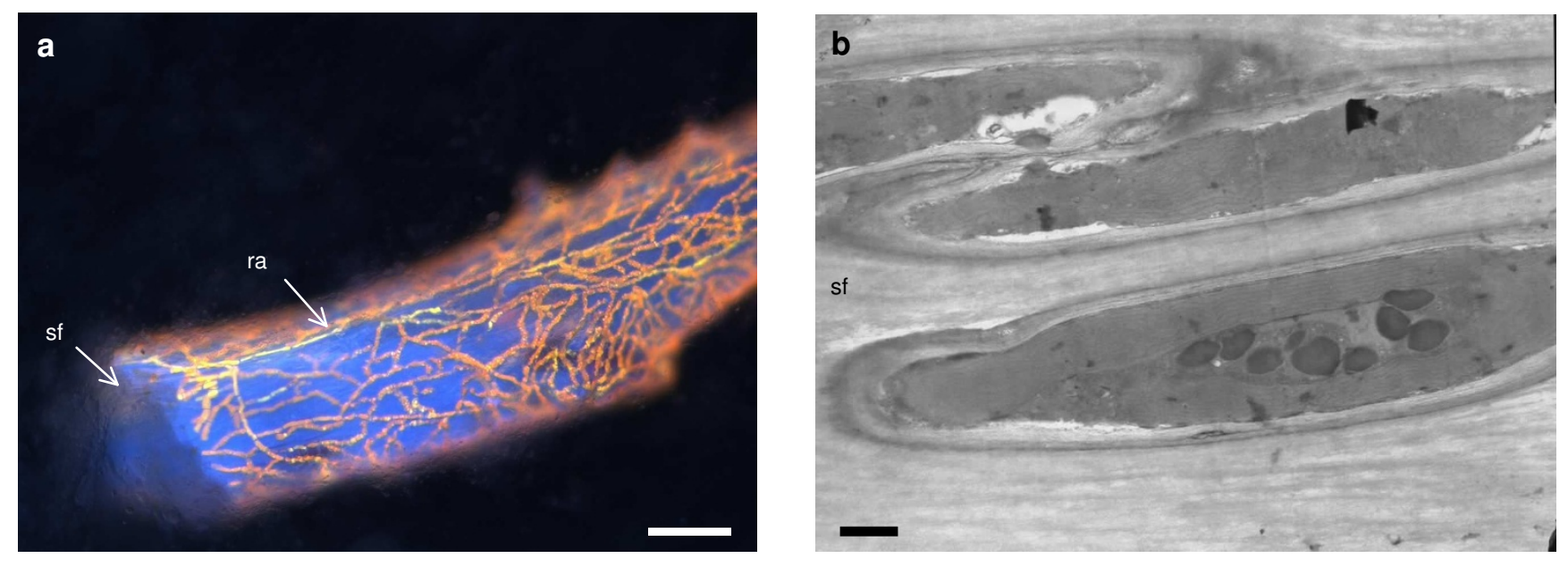

\section{Figure 4}

Rhodophyte symbiont. a) Rhodophyte autofluorescence ( $\mathrm{ra}$ ) in Mycale sp. 2 covering spongin fibres (sf), scale bar $=100 \mu \mathrm{m}$. b) TEM analysis of Mycale sp. 2 shows the rhodophytes occur inside spongin fibres (sf), scale bar $=\mathrm{I} \mu \mathrm{m}$.

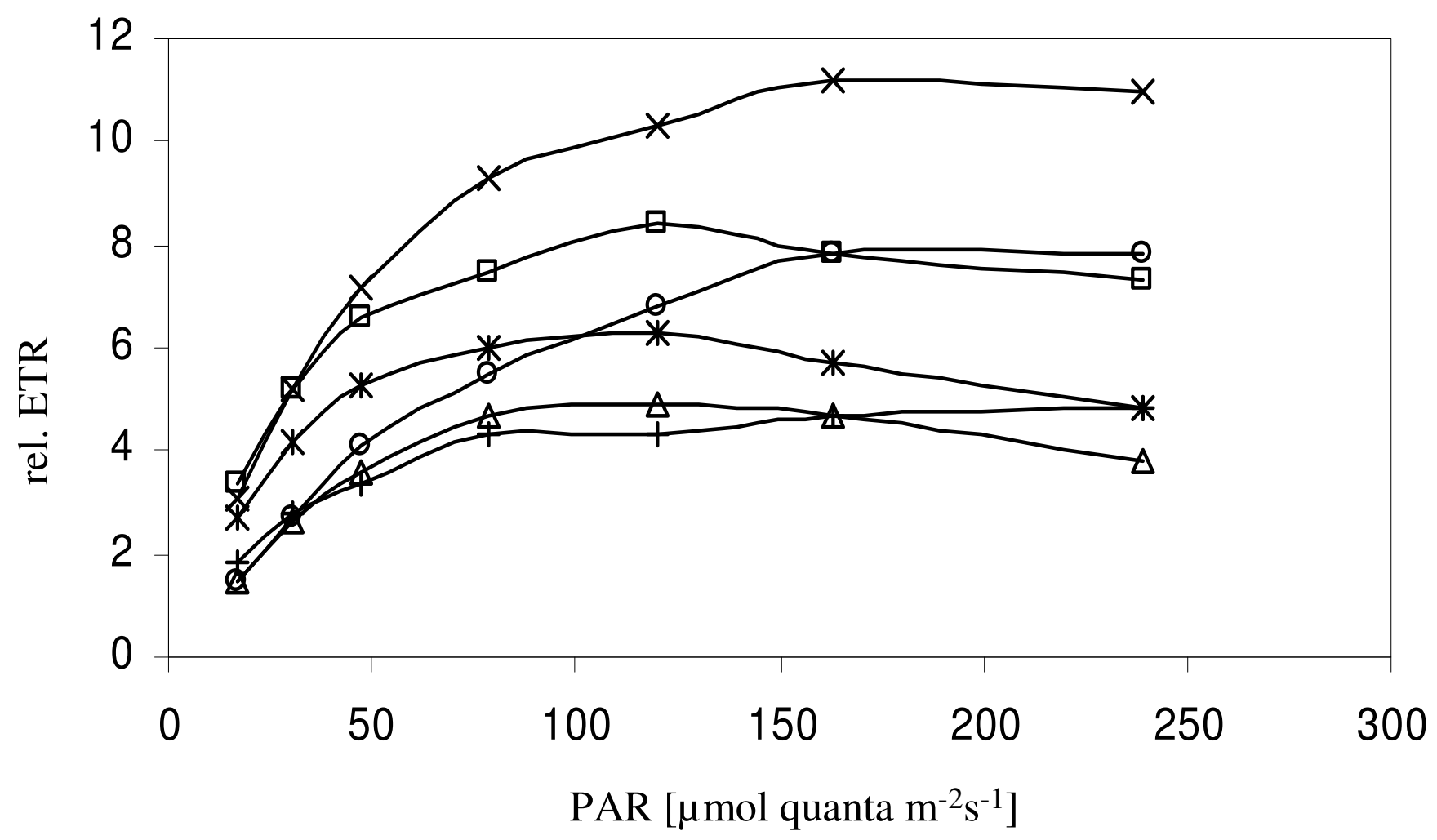

Figure 5

Light curves. Recorded light curves using PAM fluorometry: relative photosynthetic electron transport rates (rel. ETR) as a function of irradiance (measured as photosynthetic active radiation PAR) for sponge individuals growing in close proximity on the same transect. $\square$ Phyllospongia sp. containing Candidatus Synechococcus spongiarum; $\bigcirc$ Psammastra sp. containing "Candidatus Synechococcus spongiarum"; $\triangle$ Spongia sp. containing Synechocystis trididemni like symbionts; $\times$ Cymbastela marshae containing Oscillatoria sp., + Mycale sp. 2 containing a Rhodophyte and * unidentified Calcarea species containing a Synechococcus sp. 
Calcarea species and the light curve showed saturation at $120 \mu \mathrm{mol}$ quanta $\mathrm{m}^{-2} \mathrm{~s}^{-1}$ with a maximal relative ETR of 6.3. A rhodophyte symbiont was found in Mycale sp. 2 with saturation at around $240 \mu \mathrm{mol}$ quanta $\mathrm{m}^{-2} \mathrm{~s}^{-1}$ and a maximal relative ETR of 4.8 .

Rapid light curves contain information that enables the determination of quantum yields (Y) of photosystem II and induction and saturation characteristics of photosynthesis, and can therefore be used to compare sponges harboring the same symbionts under different light conditions. However, as the number of measurements for identical sponge species from different transects was too low, this analysis was not conducted. Nonetheless, the method provides an indication of the saturation characteristics of different sponge symbionts that occur close to each other in the same light conditions.

\section{Discussion}

This study is the first to demonstrate that photosynthetic sponges are abundant and diverse in a temperate region in south Western Australia. An average of $48 \%$ of species and $63 \%$ of individuals were found to be strongly photosynthetic, with an additional $16 \%$ of species and $11 \%$ of individuals having low to medium levels of photosynthetic symbionts. These percentages are comparable to those found in temperate south east Australia. Roberts and colleagues [29] estimated that over $65 \%$ of the sponges from that region may contain photosynthetic symbionts. These percentages are also comparable to those found on tropical reefs. Steindler et al. [27] found an average of $71.5 \%$ of sponge species in the Caribbean were photosynthetic, while Erwin and Thacker [41] report that over 30\% of sponge species, also in the Caribbean, were photosynthetic. Wilkinson [28] demonstrated an average of $40.2 \%$ of sponge species were photosynthetic on the Great Barrier Reef (GBR), Australia, with a similar percentage reported for the Caribbean, and Rützler [6] reported that $45 \%$ of sponges on Caribbean reefs hosted small unicellular cyanobacteria. Sponges containing photosynthetic symbionts occurred in $20-75 \%$ of sponge diversity reported at Carrie Bow Cay (Belize) [42] on $10 \mathrm{~m}$ line transects. The percentages of $48-64 \%$ photosynthetic sponges per transect observed in our study are comparable to these data.

Symbionts belonging to the "Candidatus Synechococcus spongiarum" clade were the most common cyanobacteria, however, Synechocystis species and Oscillatoria spongeliae were also found, along with other Synechococcus species and a species of red algae (Rhodophyta).

Sponge hosts containing these symbionts sometimes occurred in close proximity to one another, but it is unknown how the symbionts are acquired by their hosts.
The mode of symbiont transmission is only known for one sponge species that occurs in WA, Chondrilla australiensis, and this species transmits cyanobacterial symbionts vertically from parent to offspring via the eggs, and sometimes the sperm [19]. However, other symbioses may have different modes of transmission and acquisition of symbionts. If cyanobacterial symbionts occur in the water column sponges must be highly selective for symbiont type. Some of these symbioses are likely to be ancient, and their establishment in nutrient-rich coastal regions where free-living Synechococcus are particularly common [43] is possibly encouraged via a close, long-term association [44].

\section{" Candidatus Synechococcus spongiarum"}

The "Candidatus Synechococcus spongiarum" clade is the largest sponge-specific clade of bacterial symbionts known, and Taylor et al. [7] reported a total of 21 sponge species from which it has been sequenced. Since then Erwin and Thacker [41] have sequenced S. spongiarum in a further 9 sponge species. We found three additional sponge species, Hippospongia sp., Phyllospongia sp. and Psammastra sp. with this symbiont in high concentrations, bringing the total number of sponge species known to have this symbiont to 33 .

\section{Synechocystis trididemni}

This is the first report of Synechocystis trididemni like symbionts from temperate Australia. This symbiont was reported in the sponges Prianos aff. melanos, Spirastrella aff. decumbens, in an unidentified sponge on the Great Barrier Reef, Australia [45], and in sponges from Palau [46] and New Zealand [47]. We obtained two 16S rDNA Synechocystis sequences from each of the sponges Spongia sp. and Mycale sp. 1. The symbionts from Spongia sp. differed by only 2 base pairs, and had $97.4 \%$ and $97.2 \%$ sequence identity to $S$. trididemni from the colonial ascidian Trididemnum solidum. The two symbionts in Mycale sp. 1 were only $96.6 \%$ identical to each other, suggesting that there are two different Synechocystis species within the same sponge. When viewed with light and fluorescence microscopy two types of symbiont were observed in Mycale sp. 1, a smaller green coccoid cyanobacterium about $10 \mu \mathrm{m}$ in diameter, and a larger red coccoid symbiont approximately $15 \mu \mathrm{m}$ in diameter. Autofluorescence wavelengths also differed, suggesting differences in phycobiliprotein concentrations, despite their close proximity within the host sponge. These two symbionts possibly have maximum photosynthetic efficiencies at different wavelengths, enabling their host to grow in a wider range of light levels. Two more sponge species, Xestospongia sp. and Phorbas sp. contained relatively large coccoid cyanobacteria, resembling Synechocystis, in high concentrations. 


\section{Oscillatoria spongeliae}

The cyanobacterium Oscillatoria spongeliae is possibly best known from Dysidea sp., but has been described from a number of sponges in different areas of the world, including Palau [40] and Guam [48]. It was observed in Dysidea sp. on the Great Barrier Reef, Australia [49,50], but this is the first report of $O$. spongeliae in Western Australia, where it occurs in high densities in the surface tissues of a Chondropsis species.

\section{Unknown Symbiont}

The distinctive "hairy" cyanobacterium in Cymbastela marshae has not been observed in other sponges, or reported as free-living, but was again found in this study. Its phylogeny is uncertain, however, it has $98.6 \%$ sequence identity to Oscillatoria rosea. It occurs in high densities within the sponge and symbioses appear to be stable over time and space, having been found in Cymbastela marshae in Fremantle [26], and Busselton, WA (this study), in different years. Taylor and co-workers recently demonstrated a phylogenetic relationship with Oscillatoria rosea and the Synechococcus sp. strain PCC7002 [7].

\section{Rhodophyta}

Filamentous rhodophytes with similar gross morphology were observed in at least 7 sponge species in this study, growing through and over spongin fibres and giving them a red colouration. Similar spongin-permeating algae, Ostreobium cf. constrictum and Acrochaetium spongicolum, were described from Belize [6], and the Mediterranean [51]. Rhodophyte/sponge symbioses also occur on the Great Barrier Reef, Australia [52], and in southern Australia [5], however, in these symbioses the algae are considerably larger.

This study is the first to investigate the molecular phylogeny of rhodophyte symbionts in sponges. Our 16S rDNA sequence of this symbiont in Lissodendoryx sp. was 95\% identical to Palmaria palmata, and may be a new species. However, further work is needed to establish if all 7 sponge species host the same species of rhodophyte. Using TEM, their ultrastructure was similar to Acrochaetium spongicolum in Mycale laxissima observed by Rützler [6]. There were no indications that the rhodophytes harm the host, although this is possible as the algae are sponginboring in at least some cases. In the Haliclona cymaeformis/ Ceratodictyon spongiosum symbiosis the rhodophyte partner donates a small amount of photosynthate to the sponge host [53], and may provide support [52]. In return the rhodophyte partner benefits from the provision of nitrogen by the sponge, boosting algal growth rates in comparison to algae not in symbiosis [53]. Neither Haliclona cymaeformis or Ceratodictyon spongiosum have been observed living without the other partner [52].
Sponges containing rhodophytes included densely pigmented orange and dark grey species, and it is interesting that algae can grow successfully deep in the body of these sponges. It is possible that light is conducted to the algae by spicules, as all the sponge species containing rhodophytes in this study except Dictyodendrilla sp. have siliceous spicule bundles contained within the fibres on which the algae grow. Like cyanobacteria, but unlike most other algae, rhodophytes contain phycobiliproteins. These accessory photosynthetic proteins capture a broad range of the light spectrum and enable organisms to grow at much lower light intensities than terrestrial plants [54]. It would therefore seem that, like cyanobacteria, rhodophytes are able to grow in the low light intensities found within the matrix of sponge hosts, and are closely associated with the spongin fibres both for physical support and light transmission via the spicules. The transport of photo-active radiation via spicules was recently shown in a living Tethya aurantium [55].

\section{Levels of cyanobacterial autofluorescence}

It is interesting that different levels of cyanobacterial densities were observed in sponges in this study, ranging from low to high. Sponges with very high densities of cyanobacteria resulted in a strongly positive PAM result, while other sponges with low to medium concentrations of symbionts resulted in low to medium PAM readings. Similar observations have been made by Erwin and Thacker [41], who found low and intermediate chlorophyll a levels in sponges in the Caribbean, but the nature of this type of association is unknown. It is possible that sponges in the "low" density group retained free-living cyanobacteria from the water column on which they were feeding, either in choanocytes or other areas of the body, and for this reason they were not included in the group that was positive for photosynthetic symbionts. The cyanobacteria in the "medium" density group may also result from water column feeding, but it is not known if these are retained by the sponge over time i.e. symbionts. The cyanobacteria in one sponge from the "medium" group, a Crella sp., were closely related to free-living Synechococcus species. This may represent a nascent symbiosis in which the cyanobacterial symbionts and sponge host are negotiating the association, with symbionts being consumed more often than is usually the case. However, it is interesting to note that the unidentified Calcarea species also had symbionts closely related to free-living cyanobacteria but these occurred consistently in this species and at high concentrations.

Sponges with microbial symbionts must have regulatory mechanisms to avoid symbionts overwhelming host tissues. Several of these mechanisms have been proposed including the sponge consuming enough of the products from photosynthesis to restrict cyanobacterial growth, 
and the sponge eating or ejecting the symbionts when stressed $[7,56]$. However, we still lack a clear picture of the factors and mechanisms that control these associations. More experimental work is needed to determine spongesymbiont interactions and regulation.

The Diving PAM was a useful method for determining photosynthetic sponges in situ, and provided an indication of the density of photosynthetic symbionts in the sponge tissue.

DGGE using 16S rDNA was useful for separating and sequencing cyanobacterial symbionts where more than one species was present within a host. However, it appears that our gel would have benefited from running longer than the $31 / 2$ hours we used, as the bands for "Candidatus Synechococcus spongiarum" and Oscillatoria spongeliae were not noticeably separated. It is interesting that sponges containing more than one photosynthetic symbiont are relatively common.

\section{Occurrence of photosynthetic sponges}

There are likely to be a number of factors that influence the occurrence of photosynthetic sponges, including light conditions, sedimentation and possibly nutrient levels. In WA the Leeuwin Current transports nutrient-poor water from the tropics southwards in winter, however, this flows well offshore from our sampling sites. Chlorophyll $a$ levels in the water column at inshore locations indicate that nutrient levels remain relatively high all year, but are particularly high in the wet winter months from run-off from land, reaching $1 \mathrm{mg} \mathrm{m}^{-3}$ [34]. During the summer months the Capes Current, which begins in the Cape Leeuwin and Naturaliste region (close to our sampling sites at Busselton Jetty and Eagle Bay), is created from an upwelling of cold, nutrient-rich water [34], potentially influencing nutrient levels at our more southerly sampling sites.

Interestingly, the percentage of photosynthetic sponge species was higher at the Busselton Jetty and Eagle Bay sites than in the Perth metropolitan region. Sediment levels were noticeably higher at the latter sites, potentially affecting the success of photosynthetic sponges. Wilkinson [28] observed higher percentages of phototrophic sponges with increasing distance from land on both the GBR and in the Caribbean, perhaps also as a result of decreasing sediment load at offshore sites.

\section{Conclusion}

The high diversity and abundance of photosynthetic sponges found in this study indicates they are as important in temperate Western Australia as they are in tropical zones. Other temperate areas need to be examined to determine if WA is unusual in this respect, or if this finding can be generalized. It appears that there are three com- mon generalist clades of cyanobacterial symbionts of sponges, "Candidatus Synechococcus spongiarum", Synechocystis trididemni like symbionts, and Oscillatoria spongeliae which occur in a wide range of sponges in a wide range of environmental conditions. Further research is needed to examine the different levels of photosynthetic symbionts and the factors and mechanisms that control these associations.

\section{Authors' contributions}

ML and KU carried out transect work including the collection of sponge samples, PAM measurements in situ and microscopy. ML completed the majority of PCR analyses and drafted the manuscript. KU designed the study, carried out the DGGE and TEM analysis, organized the permissions and helped to revise the manuscript. Sponges were identified using classical techniques by JF who also helped to revise the manuscript. FB coordinated collaborations and helped to draft the manuscript. All authors read and approved the final manuscript.

\section{Acknowledgements}

$\mathrm{KU}$ was supported by a Research Grant from the University of Western Australia. ML was supported by a grant of Landesstiftung Baden-Württemberg, Germany. Many thanks to Andrew Usher for his invaluable support for this project. Sincere thanks also to Simon Toze, CSIRO Land and Water, Western Australia for providing the supplies, equipment and advice that enabled this project to be undertaken. Aspects of this project were carried out using facilities at the Centre for Microscopy, Characterisation and Analysis, The University of Western Australia, which is supported by University, State and Federal Government funding. Hydrofluoric acid treatment of sponge samples for TEM was kindly undertaken by $B$. Wilson at the University of Western Australia. This work was also supported by the research project BIOTECmarin (03F04I4D), founded by the Federal Ministry of Education and Resaerch (BMBF) and the University of Stuttgart, Germany.

\section{References}

I. Xiao S, Hu J, Yuan X, Parsley RL, Cao R: Articulated sponges from the Lower Cambrian Hetang Formation in southern Anhui, South China: their age and implications for the early evolution of sponges. Palaeogeogr Palaeoclimatol Palaeoecol 2005, 220(I2):89- I 17.

2. Hooper JN, Van Soest RWM: Systema Porifera: A guide to the classification of sponges. Kluwer Academic/Plenum Publishers; 2002.

3. Möhn E: System und Phylogenie der Lebewesen. Bd. I. Physikalische, chemische und biologische Evolution. Prokaryonta, Eukaryonta/bis Ctenophora. Schweizerbart'sche Verlagsbuchhandlung; 1984.

4. Ribes M, Coma R, Gili JM: Natural diet and grazing rate of the temperate sponge Dysidea avara (Demospongiae, Dendroceratida) throughout an annual cycle. Mar Ecol Prog Ser 1999, I 76: 179-190.

5. Scott FJ, Wetherbee R, Kraft GT: The morphology and development of some prominantly stalked southern Australian Halymeniaceae (Cryptonemiales, Rhodophyta). 2. The sponge-associated genera Thamnoclonium Kuetzing and Codiophyllum Gray. J Phycol 1984, 20(2):286-295.

6. Rützler K: Associations between Caribbean sponges and photosynthetic organisms. In New perspectives in sponge biology Edited by: Rützler K. Washington, DC: Smithsonian Institution Press; 1985:455-466. 
7. Taylor MW, Radax R, Steger D, Wagner M: Sponge-Associated Microorganisms: Evolution, Ecology, and Biotechnological Potential. Microbiol Mol Biol Rev 2007, 7 I (2):295-347.

8. Wilkinson CR: Net primary productivity in coral reef sponges. Science 1983, 219(4583):410-412.

9. Wilkinson CR: Productivity and abundance of large sponge populations on Flinders Reef flats, Coral Sea. Coral Reefs 1987, 5(4): $183-188$.

10. Arillo A, Bavestrello G, Burlando B, Sarà M: Metabolic integration between symbiotic cyanobacteria and sponges: a possible mechanism. Mar Biol 1993, II 7(1):159-162.

II. Wilkinson CR, Fay P: Nitrogen fixation in coral reef sponges with symbiotic cyanobacteria. Nature 1979 279(57|3):527-529.

12. Unson MD, Faulkner D]: Cyanobacterial symbiont biosynthesis of chlorinated metabolites from Dysidea herbacea (Porifera). Experientia Basel 1993, 49(4):349-353.

13. Schmidt EW, Obraztsova AY, Davidson SK, Faulkner DJ, Haygood MG: Identification of the antifungal peptide-containing symbiont of the marine sponge Theonella swinhoei as a novel $d$ proteobacterium, "Candidatus Entotheonella palauensis". Mar Biol 2000, I36(6):969-977.

14. Rai AN: CRC handbook of symbiotic cyanobacteria. CRC Press; 1990

15. Hentschel U, Usher KM, Taylor MW: Marine sponges as microbial fermenters. FEMS Microbiol Ecol 2006, 55(2):167-I77.

16. Herre EA, Knowlton N, Mueller UG, Rehner SA: The evolution of mutualisms: exploring the paths between conflict and cooperation. Trends Ecol Evol 1999, 14(2):49-53.

17. Usher KM, Kuo J, Fromont J, Sutton DC: Vertical transmission of cyanobacterial symbionts in the marine sponge Chondrilla australiensis (Demospongiae). Hydrobiologia 200I, 46I(I3):9-13.

18. Oren M, Steindler L, Ilan M: Transmission, plasticity and the molecular identification of cyanobacterial symbionts in the Red Sea sponge Diacarnus erythraenus. Mar Biol 2005, | 48(I):35-4I.

19. Usher KM, Sutton DC, Toze S, Kuo J, Fromont J: Inter-generational transmission of microbial symbionts in the marine sponge Chondrilla australiensis (Demospongiae). Mar Freshw Res 2005, 56(2): 125-131.

20. Enticknap I, Kelly M, Peraud O, Hill RT: Characterization of a culturable alphaproteobacterial symbiont common to many marine sponges and evidence for vertical transmission via sponge larvaef. Appl Environ Microbiol 2006, 72(5):3724-3732.

21. Vacelet J, Donadey C: Electron microscope study of the association between some sponges and bacteria. J Exp Mar Biol Ecol |977, 30:30|-3|4.

22. Wilkinson CR, Garrone R, Vacelet J: Marine sponges discriminate between food bacteria and bacterial symbionts: electron microscope radioautography and in situ evidence. Proc $R$ Soc Lond B Biol Sci 1984, 220(1 22I):519-528.

23. Wehrl M, Steinert M, Hentschel U: Bacterial uptake by the marine sponge Aplysina aerophoba. Microb Ecol 2007, 53(2):355-365.

24. Hentschel U, Hopke J, Horn M, Friedrich AB, Wagner M, Hacker J, Moore BS: Molecular evidence for a uniform microbial community in sponges from different oceans. Appl Environ Microbio 2002, 68(9):443।-4440.

25. Usher KM, Toze S, Fromont J, Kuo J, Sutton DC: A new species of cyanobacterial symbiont from the marine sponge Chondrilla nucula. Symbiosis 2004, 36(2): $183-192$.

26. Usher KM, Fromont J, Sutton DC, Toze S: The biogeography and phylogeny of unicellular cyanobacterial symbionts in sponges from Australia and the Mediterranean. Microb Ecol 2004 48(2): 167-177.

27. Steindler L, Beer S, llan M: Photosymbiosis in intertidal and subtidal tropical sponges. Symbiosis 2002, 33(3):263-273.

28. Wilkinson CR: Interocean differences in size and nutrition of coral reef sponge populations. Science 1987 236(4809): 1654-1657.

29. Roberts DE, Cummins SP, Davis AR, Pangway C: Evidence for symbiotic algae in sponges from temperate coastal reefs in New South Wales Australia. Mem Queensl Mus 1999, 44:493-497.
30. Webster NS, Negri AP, Munro MMHG, Battershill CN: Diverse microbial communities inhabit Antarctic sponges. Environ Microbiol 2004, 6(3):288-300.

31. Cerrano C, Arillo A, Bavestrello G, Calcinai B, Cattaneo-Vietti R, Penna A, Sarà M, Totti C: Diatom invasion in the antarctic hexactinellid sponge Scolymastra joubini. Polar Biol 2000, 23(6):44|-444.

32. Cerrano C, Calcinai B, Cucchiari E, Di Camillo C, Totti C, Bavestrello G: The diversity of relationships between Antarctic sponges and diatoms: the case of Mycale acerata Kirkpatrick 1907 (Porifera, Demospongiae). Polar Biol 2004, 27(4):23I-237.

33. Bavestrello G, Arillo A, Calcinai B, Cattaneo-Vietti R, Cerrano C Gaino $E$, Penna A, Sarà M: Parasitic diatoms inside antarctic sponges. Biol Bull 2000, I 98(I):29-33.

34. Lourey MJ, Dunn JR, Waring J: A mixed-layer nutrient climatology of Leeuwin Current and Western Australian shelf waters: Seasonal nutrient dynamics and biomass. J Mar Syst 2006, 59(I-2):25-5I.

35. Spurr AR: A low-viscosity epoxy resin embedding medium for electron microscopy. J Ultrastruct Res 1969, 26(I):3 I-43.

36. Reynolds ES: The use of lead citrate at high $\mathrm{pH}$ as an electronopaque stain in electron microscopy. J Cell Biol 1963, I7(I):208-212

37. Nübel U, Garcia-Pichel F, Muyzer G: PCR primers to amplify I6S rRNA genes from cyanobacteria. Appl Environ Microbiol 1997. 63(8):3327-3332

38. Diaz MC: Molecular and ecological studies of sponge-microbial associations. PhD Thesis, University of California, Santa Cruz. University of California, Santa Cruz; 1996.

39. Altschul SF, Madden TL, Schaffer AA, Zhang J, Zhang Z, Miller W, Lipman D]: Gapped BLAST and PSI-BLAST: a new generation of protein database search programs. Nucleic Acids Res 1997, 25( I 7):3389-3402

40. Ridley CP, Bergquist PR, Harper MK, Faulkner DJ, Hooper JN, Haygood MG: Speciation and biosynthetic variation in four dictyoceratid sponges and their cyanobacterial symbiont, Oscillatoria spongeliae. Chem Biol 2005, I 2(3):397-406.

4I. Erwin PM, Thacker RW: Incidence and identity of photosynthetic symbionts in Caribbean coral reef sponge assemblages. J Mar Biol Ass UK Spec 2007:1683-1692.

42. Diaz MC, Rützler K: Sponges: An essential component of Caribbean coral reefs. Bull Mar Sci 200I, 69(2):535-546.

43. Agawin NSR, Duarte CM, Agusti' S, McManus L: Abundance, biomass and growth rates of Synechococcus sp. in a tropical coastal ecosystem (Philippines, South China Sea). Estuar Coast Shelf Sci 2003, 56(3-4):493-502.

44. Usher KM, Bergman B, Raven JA: Exploring cyanobacterial mutualisms. Annu Rev Ecol Evol Syst 2007, 38:255-273.

45. Cox GC, Hiller RG, Larkum AWD: An unusual cyanophyte, containing phycourobilin and symbiotic with ascidians and sponges. Mar Biol 1985, 89(2):149-163.

46. Ridley CP, John Faulkner D, Haygood MG: Investigation of Oscillatoria spongeliae-dominated bacterial communities in four dictyoceratid sponges. Appl Environ Microbiol 2005, 7I(II):7366-7375.

47. Webb VL, Maas EW: Sequence analysis of I6S rRNA gene of cyanobacteria associated with the marine sponge Mycale (Carmia) hentscheli. FEMS Microbiol Lett 2002, 207(I):43-47.

48. Thacker RW, Starnes S: Host specificity of the symbiotic cyanobacterium Oscillatoria spongeliae in marine sponges, Dysidea spp. Mar Biol 2003, I 42(4):643-648.

49. Larkum AWD, Cox GC, Hiller RG, Parry DL, Dibbayawan TP: Filamentous cyanophytes containing phycourobilin and in symbiosis with sponges and an ascidian of coral reefs. Mar Biol 1987, 95(1):1-13.

50. Hinde R, Pironet F, Borowitzka MA: Isolation of Oscillatoria spongeliae, the filamentous cyanobacterial symbiont of the marine sponge Dysidea herbacea. Mar Biol I994, I I 9(I):99-104.

51. Sarà M: Associazioni fra Poriferi e alghe in acque superficiali del litorale marino. Ricerca Scient 1966, 36:277-282.

52. Trautman DA, Hinde R, Borowitzka MA: Population dynamics of an association between a coral reef sponge and a red macroalgae. J Exp Mar Biol Ecol 2000, 244(I):87-I05.

53. Davy SK, Trautman DA, Borowitzka MA, Hinde R: Ammonium excretion by a symbiotic sponge supplies the nitrogen 
requirements of its rhodophyte partner. J Exp Biol 2002, 205(22):3505-35II.

54. Wyman M, Fay P: Underwater light climate and the growth and pigmentation of planktonic blue-green algae (cyanobacteria) $I$. The influence of light quantity. Proc $R$ Soc Lond B Biol Sci 1986, 227( ( 248):367-380.

55. Brümmer F, Pfannkuchen M, Balz A, Hauser T, Thiel V: Light inside sponges. J Exp Mar Biol Ecol 2008, 367:6I-64.

56. Wilkinson CR: Symbiotic interactions between marine sponges and algae. In Algae and symbioses: plants, animals, fungi, viruses, interactions explored Edited by: Reisse W. Bristol: Biopress Limited; |992:|II-I5I.

Publish with Bio Med Central and every scientist can read your work free of charge

"BioMed Central will be the most significant development for disseminating the results of biomedical research in our lifetime. "

Sir Paul Nurse, Cancer Research UK

Your research papers will be:

- available free of charge to the entire biomedical community

- peer reviewed and published immediately upon acceptance

- cited in PubMed and archived on PubMed Central

- yours - you keep the copyright

Submit your manuscript here:

http://www.biomedcentral.com/info/publishing_adv.asp
BioMedcentral 